\title{
Constructing the best supply chain process model of logistics for Free Trade Port Zone
}

\author{
Dingtao Zhao ${ }^{1, a}$, Su-Hui Kuo ${ }^{1, b}$, Tien-Chin Wang ${ }^{2, c^{*}}$ \\ ${ }^{1}$ University of Science and Technology of China, Hefei, Anhui 230026, China \\ ${ }^{2}$ National Kaohsiung University of Applied Sciences, 415 Chien Kung Road, Kaohsiung 80778, \\ Taiwan
}

aemail: box@ustc.edu.cn, bemail: kcsophia@yahoo.com.tw, cemail: tcwang@kuas.edu.tw

*Corresponding author

Keywords: InLinPreRa; Multi-Criteria Decision Making; Free Trade Port Zone; Supply Chain.

\begin{abstract}
With the development trend of international logistics, international logistics of Ports and Harbors International's role is more important, Stevedoring function is no longer just offer traditional type of transit transport function, whether the goods imported from abroad, the domestic manufacturers export cargo transit, in dire need of a logistics center adjacent areas of Ports and Harbors provided and equipment, packaging, storage, simple processing, information and other type of transport logistics and distribution services. Based on our country and other countries developing their own conditions and background out of free trade harbor operations and management are different, our Free Trade Zone offers two features not found in other countries, which provides free access to business professionals Port of convenience as well as in the deep processing of high value-added free trade zone, we can see for the logistics industry, if you can successfully integrate deep processing supply chain, relatively can enhance international competitiveness. Based on this present study aims to understand the Kaohsiung Free Trade Zone in the international competition trends, best of deep processing supply chain assessment model, and to explore Kaohsiung Harbor Free Trade Zone itself how to use the advantages of the location and the system, and the surrounding supply chain combine different strengths and characteristics, adjusting management system, construction of integrated information system to facilitate the operation, to enable enterprises to enhance their competitiveness, relative to drive Kaohsiung continue to forge ahead, the layout of East Asia, the continent forward logistics base and a global network of industrial cluster The recommendations and other free trade zone as demonstration models.
\end{abstract}

\section{Introduction}

Yang, Y.-C. (2009) research indicated that the functions of port-type FTZs should be coordinated with local industrial development models based on a port cluster perspective. The Taiwan custom authority should ease existing inspection regulations and mechanisms to ensure the freedom of operating activities and management systems in the FTZ. [1]

Slack, B. and A. Fremont (2005) indicated that concludes by discussing some of the implications of the findings, including the issue of monopoly control of ports and the potential for conflict between the two models of contemporary cargo handling.[2]

Competitions between ports are gradually evolving into competitions between supply chains, with ports no longer considered as isolated links in the transport chain but rather as integral links in the supply chain [3]. Yang, Y.-C. and S.-L. Chen used the analytical hierarchy process (AHP) and gray relational analysis (GRA) to determinants of global logistics hub ports. A total of 20 assessment criteria are obtained under the five dimensions of political-economic environment, operating environment, cost environment, infrastructure facilities environment, and preferential incentive environment. The AHP results show that, from the perspective of all respondents, the top five assessment criteria are transport and distribution costs, convenience of customs clearance procedures, harbor and stevedoring costs, cost of land, and soundness of investment system and 
incentive measures [4]. In the face of an increasingly integrated global economy, the Kaohsiung has progressively upgraded the country's so-called free-trade zones (FTZs) to attract greater foreign investment. Based on this present study aims to understand the Kaohsiung Free Trade Zone in the international competition trends, best of deep processing supply chain assessment model, and to explore Kaohsiung Harbor Free Trade Zone itself how to use the advantages of the location and the system, and the surrounding supply chain combine different strengths and characteristics, adjusting management system, construction of integrated information system to facilitate the operation, to enable enterprises to enhance their competitiveness, relative to drive Kaohsiung continue to forge ahead, the layout of East Asia, the continent forward logistics base and a global network of industrial cluster The recommendations and other free trade zone as demonstration models. Hsu \& Wang (2011) solved a multi-criteria decision making problem with incomplete linguistic preference relations by using method [5]. Wang et al. (2011) using the group decision making matrix in the selection of business location [6]. It is important issue to select the best Logistics service supply chain process model for Kaohsiung Free Trade Port Zone. This study applies the Incomplete Linguistic Preference Relations (InLinPreRa) analytical framework to measuring the Optimized Logistics service supply chain process model for Kaohsiung Free Trade Port Zone as well as to verify the feasibility of this proposed approach. This model not only serves as a checking the best supply chain, but also helps in analyzing the organizational ability by considering key success factors.

\section{Literature Review}

\section{Free Trade Port Zone}

Five factors were found to have a high degree of importance for business operations in FTPZs: government administration efficiency, cheap rates and charges, simplified customs procedures, clear regulations, and free tax incentives. Further, results indicated that firms in FTPZ had increased their performance in terms of reputation, investment, customer satisfaction, and revenue. The study provides insight into the evaluation and policy suggestions of FTPZ for government in Taiwan [7]. Yang, Y.-C research findings as follows: (1) Existing container terminals in Taiwan confronted with serious land shortage problems need to revise terminal layout and construction from a port hinterland perspective as well as Korea' modal. (2) The functions of port-type FTZs should be coordinated with local industrial development models based on a port cluster perspective. (3) The Taiwan custom authority should ease existing inspection regulations and mechanisms to ensure the freedom of operating activities and management systems in the FTZ [1]. The government also launched and formulated a set of strategic designs and organizational changes, namely, the Asia-Pacific Regional Operations Centre (APROC) in 1995 and the Offshore Transshipments Canter in Kaohsiung in 1997 [7].

\section{Incomplete Linguistic Preference Relations (InLinPreRa)}

$\mathrm{Xu}$ [8] presented linguistic preference relations are usually used by decision makers to express their linguistic preference information based on pairwise comparisons. $\mathrm{Xu}$ [9] proposed the Incomplete Linguistic Preference Relations. Wang and Hsu used the Incomplete Linguistic Preference Relations to constructed Multi-Criteria Decision Making [10]. Linguistic preference relations are usually used by decision makers to express their linguistic preference information based on pairwise comparisons [9, 11].The relevant definitions are as follows:

Definition1. Incomplete Linguistic Preference Additive Relation

Let $A=\left(a_{i j}\right)_{n \times n}$ be linguistic preference relation, if $A$ is an incomplete linguistic preference relation, it counters the fact that decision makers can carry out pairwise comparison for attributes so as to satisfy Eq.(1)

$a_{i j} \in S, \quad a_{i j} \oplus a_{j i}=S_{0}, \quad a_{i i}=S_{0}$

Definition2. Incomplete Linguistic Consistent Additive Preference Relation

Let $A=\left(a_{i j}\right)_{n \times n}$ be complete consistent additive preference relation, which counters all of the 
$i, j, k$ decision makers for pairwise comparison, if $a_{i k}>S_{0}$ represents $x_{i}$ is better than $x_{k}$; while $a_{k j}>S_{0}$ represents $x_{k}$ is better than $x_{j}$, then $a_{i j}>S_{0}$ can be derived the equation of $x_{i}$ better than $x_{j}$ is

$a_{i j}=a_{i k} \oplus a_{k j}$

If $a_{i j}=S_{0}, a_{i j}=0$ represents $x_{i}$ and $x_{j}$ are the same, both of them can satisfy $a_{i k}=a_{k j}=a_{i j}=S_{0}$.

\section{Methodology: Constructed the best supply chain process model of logistics Decision Making Matrix}

Step 1: Confirm the evaluation criteria, decision making experts, and number of alternatives.

Let there are nth decision making experts in the evaluation process, where $\mathrm{E}_{e}$ represents $(e=1,2, \ldots, n)$, with $k$ th evaluation criteria, where $\mathrm{C}_{r}$ represents $(r=1,2, \ldots, k)$, with $m$ th alternatives, where $\mathrm{A}_{i}, \mathrm{~A}_{j}$ represents $(i, j=1,2, \ldots, m)$.

Step 2: Select the appropriate linguistic variables, their mapping values between $[-t, t]$

Step 3: Construct decision making group to sift evaluation criterion weight out

${ }^{1} w,{ }^{2} w, \ldots,{ }^{k} w,{ }^{r} w \in[0,1], \sum_{r=1}^{k}{ }^{r} w=1$

Step 4: Determine the weight of decision making expert $w^{(1)}, w^{(2)}, \ldots, w^{(n)}, w^{(e)} \in[0,1]$, and $\sum_{e=1}^{n} w^{(e)}=1$

Step 5: Utilize the algorithm rules of the preference relation's pairwise comparison to integrate all of the decision makers' evaluations towards all of the alternatives under each criterion.

1. The $e$ th expert under the $r$ th criterion, the decision making matrix for the $m$ th alternative is represented by ${ }^{r} \mathrm{D}^{(e)}=\left[{ }^{r} a_{i j}^{(e)}\right]_{m \times m}$ as

$$
\begin{aligned}
& \begin{array}{llllll}
\mathrm{A}_{1} & \mathrm{~A}_{2} & \mathrm{~A}_{3} & \mathrm{~A}_{4} & \cdots & \mathrm{A}_{m}
\end{array}
\end{aligned}
$$

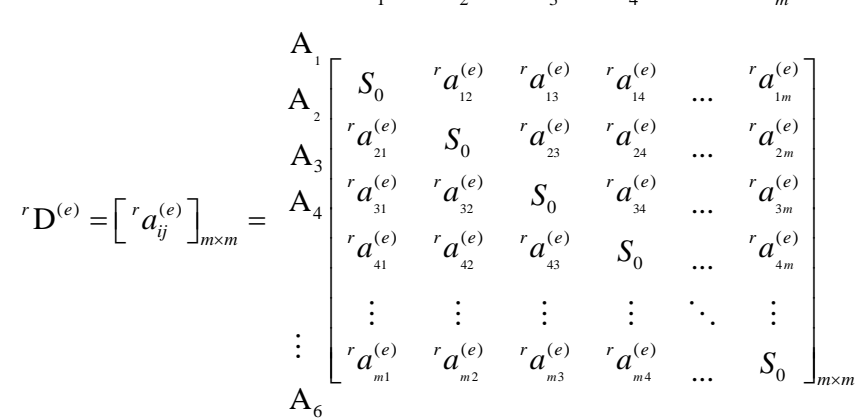

2. Utilizing the algorithm rule of pairwise comparison to get the mapping values of all of the absent matrices through Eq. (1) $a_{i j} \oplus a_{j i}=S_{0}$, and then all of the $\times$ unknown variables will be derived by Eq. (2) $a_{i j}=a_{i k} \oplus a_{k j}$, so as to derive out the complete matrix.

3. Multiply the complete matrix by criterion weight ${ }^{r} w$, each expert's average preference matrix can be obtained, which is represented by $\overline{\mathrm{D}}^{(e)}$.

$$
\overline{\mathrm{D}}^{(e)}=\frac{1}{k}\left[\sum_{i=1}^{k}{ }^{r} \mathrm{D}^{(e)} \otimes{ }^{r} w\right]
$$

Step 6: Integrate all of the alternatives' evaluation values that are appraised by all of the decision making experts.

Multiply the average preference matrix $\overline{\mathrm{D}}^{(e)}$ of each expert by its corresponding expert weight $w^{(e)}$, derives the decision making matrix are integration, which is represented by $\overline{\overline{\mathrm{D}}}$ :

$$
\overline{\overline{\mathrm{D}}}=\frac{1}{n}\left[\overline{\mathrm{D}}^{(1)} \otimes w^{(1)}+\overline{\mathrm{D}}^{(2)} \otimes w^{(2)}+\ldots+\overline{\mathrm{D}}^{(n)} \otimes w^{(n)}\right]=\frac{1}{n}\left[\sum_{e=1}^{n} \overline{\mathrm{D}}^{(e)} \otimes w^{(e)}\right]
$$


Step 7: Rank all of the alternatives' evaluation values so as to select the best supply chain process model of logistics result

All of the optimized logistics service supply chain alternatives' evaluation values are weighted, averaged, and ranked, in order to obtain the best evaluation result.

\section{Illustrative Example}

In the fierce competitive and rapid changing business environment, how a company could still maintain a stable operating growth while facing highly competitive stress from industry even achieve a 10 times growth has become an important lesson that a company must confront. Generally speaking, essential factors to enhance the growth of operation are abilities of research and development, purchasing, services, marketing and selling. Among them, the ability of marketing and selling is regarded as the key factor that spurs a company to grow. It brings about not only the best managing goal of the entire supplement chain but also the specialization and appreciation of service. The topic of modern management of logistics cost and service, that is, trying to raise the service quality and appreciation on the base of cutting down the cost. On service, there is an objective display called 7R principle, which includes Right Quality, Right Quantity, Right Time, Right Place, Right Impression, Right Price, and Right Commodity. These seven principles exactly provide services from seven aspects for customers.

This research constructs the best supply chain process model of logistics for Free Trade Port Zone based on both cost and service. This work process and result in the following:

First the expert questionnaire is used to be directed against three decision experts, and five (represent by A, B, C, D, and E) are countered for evaluation. Confirm the evaluation criteria, decision making experts, and number of alternatives. There are three decision making experts in the evaluation process, where $\mathrm{E}_{e}$ represents $(e=1,2,3)$, with four evaluation criteria, where $\mathrm{C}_{r}$ represents $(r=1,2, \ldots, 4)$, with five alternatives, where $\mathrm{A}_{i}, \mathrm{~A}_{j}$ represents $(i, j=1,2, \ldots, 5)$. Then direct against three decision making experts through assumed expert questionnaires, they choose a definite criterion according to their own preferences, under the four criteria, five tourism destination (represent by A, B, C, D, and E) are evaluated, and then pairwise comparison is carried out. Integrate all of the alternatives' evaluation values that are apprised by all of the decision making experts. After integrating the above-mentioned steps, multiply the matrix by its corresponding expert weight $w^{(e)}$ according to Eq. (4) the obtained matrix is. Rank all of the alternatives' evaluation values All of the alternatives' evaluation values are averaged so as to obtain the preference values and rankings for each alternative. Which ranks the five alternatives are $\mathrm{C}>\mathrm{A}>\mathrm{E}>\mathrm{D}>\mathrm{B}$.

\section{Conclusion}

This research constructed the best supply chain process model of logistics for Free Trade Port Zone. The results gave government to understand the accompanying business and trend with scientific judgments.

This study is based on raising the competitiveness of Kaohsiung Harbor after it had been set up as a free trade zone. What's more, analyze its inside and outside surrounding and also collect some information about setting free trade zone from other neighboring countries and compare them. Then, find out the advantages for Kaohsiung Harbor to develop free trade zone and some operating odds for future in order to view its management plots and come up with some solutions.

Could gain important and influential factors and tragedy analysis with the success of free trade zone raising its international competitiveness, and provide consult and revolutions for decision-makers and companies when they against to challenges and problems.

Understanding how to enhance advantages of logistics industry of Kaohsiung Harbor free trade zone and implement the enterprise philosophy which has been bogged down for a while. That is, giving an advice of the policy should be towards to carry out the change of connecting the city and 
the port together.

After investigating and collecting important and influential factors and weights with the success of free trade zone raising its international competitiveness, figure out the best project of the supplement chain for the logistics industry and comprehend how those factories in Kaohsiung Harbor operate in practice, integrate with supplement chain and manage, which leading to create the higher additional value. Besides, to find out how logistics industry integrates logistics, cash flow, information flow and other value-added services between domestic and foreign companies, which could make managers, keep control with the situation to supplement and demand at any time. Also, this would help the company to win relative superiority during the fierce competition.

Construct Analysis of Performance Evaluation Model to help managers to understand the rank of several essential factors of the performance evaluation and the total performance ranking. With the model, companies could know the best project and have an objective analysis.

\section{References}

[1] Y.-C. Yang. A Comparative Analysis of Free Trade Zone Policies in Taiwan and Korea based on a Port Hinterland Perspective. The Asian Journal of Shipping and Logistics, 2009(25) 273-303.

[2] B. Slack and A. Fremont. Transformation of port terminal operations: From the local to the global. Transport Reviews, 2005(25) 117-130.

[3] Z. Wan, Y. Zhang, X. F. Wang, and J. H. Chen. Policy and politics behind Shanghai's Free Trade Zone Program. Journal of Transport Geography, 2014(34) 1-6.

[4] Y.-C. Yang and S.-L. Chen. Determinants of global logistics hub ports: Comparison of the port development policies of Taiwan, Korea, and Japan.Transport Policy, 2016(45) 179-189.

[5] S.-C. Hsu and T.-C. Wang. Solving multi-criteria decision making with incomplete linguistic preference relations. Expert Systems with Applications, 2011(38) 10882-10888.

[6] T.-C. Wang, S.-C. Hsu, and H.-C. Chen. Using the group decision making matrix in the selection of business location. in 2011 International Conference on Machine Learning and Cybernetics, ICMLC 2011, July 10, 2011, Guilin, Guangxi, China, 2011 1072-1076.

[7] R.-H. Chiu, T.-C. Lirn, C.-Y. Li, B.-Y. Lu, and K.-C. Shang. An evaluation of Free Trade Port Zone in Taiwan. The Asian Journal of Shipping and Logistics, 2011(27) 423-445.

[8] Z. Xu. Deviation measures of linguistic preference relations in group decision making. Omega, 2005(33) 249-254.

[9] Z. Xu. Incomplete linguistic preference relations and their fusion. Information Fusion, 2006(7) 331-337.

[10] T. C. Wang, S. C. Hsu, and Y. C. Chiang. Multi-criteria decision making with expansion of incomplete linguistic preference relations. WSEAS Transactions on Mathematics, 2007(6) 817-823.

[11] Z. Xu. A method for multiple attribute decision making with incomplete weight information in linguistic setting. Knowledge-Based Systems, 2007(20) 719-725. 